\title{
A Novel Inflammation-Based Stage (I Stage) in Patients with Resectable Esophageal Squamous Cell Carcinoma
}

\author{
Peng-Cheng Chen and Ji-Feng Feng \\ Department of Thoracic Surgery, Zhejiang Cancer Hospital, Hangzhou 310022, China \\ Correspondence should be addressed to Ji-Feng Feng; fengjif@163.com
}

Received 23 February 2016; Accepted 29 March 2016

Academic Editor: Czar L. Gaston

Copyright ( 2016 P.-C. Chen and J.-F. Feng. This is an open access article distributed under the Creative Commons Attribution License, which permits unrestricted use, distribution, and reproduction in any medium, provided the original work is properly cited.

\begin{abstract}
Background. Inflammation plays a key role in cancer. In the current study, we proposed a novel inflammation-based stage, named I stage, for patients with resectable esophageal squamous cell carcinoma (ESCC). Methods. Three hundred and twenty-three patients with resectable ESCC were enrolled in the current study. The I stage was calculated as follows: patients with high levels of C-reactive protein $(\mathrm{CRP})(>10 \mathrm{mg} / \mathrm{L})$, neutrophil-to-lymphocyte ratio (NLR) $(>3.5)$, and platelet-count-to-lymphocyte ratio (PLR) $(>150)$ were defined as I3. Patients with two, one, or no abnormal value were defined as I2, I1, or I0, respectively. The prognostic factors were evaluated by univariate and multivariate analyses. Results. There were 112 patients for I0, 97 patients for I1, 66 patients for I2, and 48 patients for I3, respectively. The 5 -year cancer-specific survival (CSS) in patients with I0, I1, I2, and I3 was $50.0 \%, 30.9 \%, 18.2 \%$, and $8.3 \%$, respectively (I0 versus I1, $P=0.002$; I1 versus I2, $P=0.012$; I2 versus $\mathrm{I} 3, P=0.020$ ). Multivariate analyses revealed that I stage was an independent prognostic factor in patients with resectable ESCC $(P<0.001)$. Conclusion. The inflammation-based stage (I stage) is a novel and useful predictive factor for CSS in patients with resectable ESCC.
\end{abstract}

\section{Introduction}

The cancer incidence and mortality have been increasing worldwide. Esophageal cancer (EC) is one of the most common cancers and remains the 4th leading cause of cancer death [1]. There are two major histologic types of EC: esophageal squamous cell carcinoma (ESCC) and esophageal adenocarcinoma (EAC). ESCC is the most common pathological type in China $[2,3]$. However, the prognosis for patients with ESCC is still poor [3]. Therefore, assessing the prognostic factors in ESCC patients will become more and more important.

Recent reports revealed that inflammation plays an important role in cancer $[4,5]$. Therefore, a series of inflammation-based biomarkers, such as C-reactive protein (CRP), neutrophil-to-lymphocyte ratio (NLR), and platelet-countto-lymphocyte ratio (PLR), have been analysed in various cancers [6-11]. However, the prognostic values of these biomarkers in patients with ESCC remain uncertain [12-17]. In addition, most of these studies only evaluated one or two biomarkers without considering others. In the current study, therefore, we proposed a novel inflammation-based stage, named I stage (combination of CRP, NLR, and PLR), for predicting the prognosis for patients with resectable ESCC.

\section{Patients and Methods}

A retrospective analysis was conducted for patients with ESCC in our hospital from January 2005 to December 2008. Patients with ESCC were confirmed by histopathology. All patients underwent surgery with curative esophagectomy and standard lymphadenectomy. Patients who had received preoperative therapy were excluded. Patients with any form of acute infection or chronic inflammatory disease were also excluded. At last, 323 patients were enrolled in our study. In the current study, a cancer-specific survival (CSS) analysis was ascertained. The last follow-up was on 30 June 2013. This study was approved by the Ethical Committees of Zhejiang Cancer Hospital (Hangzhou, China). All patients were staged according to the 7th edition of the American Joint Committee on Cancer (AJCC) Cancer Staging [18]. 
TABLE 1: Clinicopathological characteristics for patients with ESCC.

\begin{tabular}{|c|c|}
\hline & Cases $(n, \%)$ \\
\hline Age (years, mean \pm SD) & $59.1 \pm 7.9$ \\
\hline \multicolumn{2}{|l|}{ Gender } \\
\hline Female & $42(13.0)$ \\
\hline Male & $281(87.0)$ \\
\hline Tumor length $(\mathrm{cm}$, mean $\pm \mathrm{SD})$ & $4.3 \pm 1.9$ \\
\hline \multicolumn{2}{|l|}{ Tumor location } \\
\hline Upper & $17(5.3)$ \\
\hline Middle & $151(46.7)$ \\
\hline Lower & $155(48.0)$ \\
\hline \multicolumn{2}{|l|}{ Differentiation } \\
\hline Good & $44(13.6)$ \\
\hline Moderate & $216(66.9)$ \\
\hline Poor & $63(19.5)$ \\
\hline \multicolumn{2}{|l|}{$\mathrm{T}$ grade } \\
\hline $\mathrm{T} 1$ & $55(17.0)$ \\
\hline $\mathrm{T} 2$ & $55(17.0)$ \\
\hline $\mathrm{T} 3$ & $179(55.4)$ \\
\hline $\mathrm{T} 4$ & $34(10.6)$ \\
\hline \multicolumn{2}{|l|}{$\mathrm{N}$ stage } \\
\hline No & $174(53.9)$ \\
\hline N1 & $87(26.9)$ \\
\hline $\mathrm{N} 2$ & $37(11.5)$ \\
\hline $\mathrm{N} 3$ & $25(7.7)$ \\
\hline \multicolumn{2}{|l|}{ TNM stage } \\
\hline I & $81(25.1)$ \\
\hline II & $104(32.2)$ \\
\hline III & $138(42.7)$ \\
\hline \multicolumn{2}{|l|}{ I stage } \\
\hline I0 & $112(34.7)$ \\
\hline I1 & $97(30.0)$ \\
\hline $\mathrm{I} 2$ & $66(20.4)$ \\
\hline $\mathrm{I} 3$ & $48(14.9)$ \\
\hline $\mathrm{CRP}(\mathrm{mg} / \mathrm{L}$, mean $\pm \mathrm{SD})$ & $9.7 \pm 13.5$ \\
\hline $\operatorname{NLR}($ mean $\pm \mathrm{SD})$ & $3.3 \pm 2.8$ \\
\hline $\operatorname{PLR}($ mean $\pm \mathrm{SD})$ & $160.9 \pm 70.6$ \\
\hline
\end{tabular}

Routine laboratory results (including CRP, neutrophil, lymphocyte, and platelet count) were extracted in retrospective medical records. The definitions of NLR and PLR were described as follows: NLR is neutrophil-to-lymphocyte ratio and PLR is platelet-count-to-lymphocyte ratio. The cut-off values for CRP, NLR, and PLR were $10 \mathrm{mg} / \mathrm{L}, 3.5$, and 150 according to the previous studies $[12,13,16,17]$. Therefore, the I stage was calculated as follows: patients with high levels of CRP ( $>10 \mathrm{mg} / \mathrm{L})$, NLR $(>3.5)$, and PLR $(>150)$ were defined as I3. Patients with two, one, or no abnormal value were defined as I2, I1, or I0, respectively.

2.1. Statistical Analysis. The 5-year CSS was analysed by the Kaplan-Meier method. Univariate and multivariate Cox analyses were performed to analyse the prognostic factors.
TABLE 2: The relationship between I stage and clinicopathological characteristics.

\begin{tabular}{|c|c|c|c|c|c|}
\hline & $\begin{array}{l}\text { I stage } 0 \\
(n=112)\end{array}$ & $\begin{array}{l}\text { I stage } 1 \\
(n=97)\end{array}$ & $\begin{array}{l}\text { I stage } 2 \\
(n=66)\end{array}$ & $\begin{array}{l}\text { I stage } 3 \\
(n=48)\end{array}$ & $P$ value \\
\hline Age (years) & & & & & 0.817 \\
\hline$\leq 60$ & 66 & 58 & 37 & 25 & \\
\hline$>60$ & 46 & 39 & 29 & 23 & \\
\hline Gender & & & & & 0.375 \\
\hline Female & 18 & 14 & 5 & 5 & \\
\hline Male & 94 & 83 & 61 & 43 & \\
\hline Tumor length $(\mathrm{cm})$ & & & & & $<0.001$ \\
\hline$\leq 3$ & 45 & 31 & 9 & 4 & \\
\hline$>3$ & 67 & 66 & 57 & 44 & \\
\hline Tumor location & & & & & 0.488 \\
\hline Upper & 8 & 4 & 1 & 4 & \\
\hline Middle & 51 & 49 & 28 & 23 & \\
\hline Lower & 53 & 44 & 37 & 21 & \\
\hline Vessel involvement & & & & & 0.385 \\
\hline Negative & 99 & 79 & 54 & 38 & \\
\hline Positive & 13 & 18 & 12 & 10 & \\
\hline Perineural invasion & & & & & 0.043 \\
\hline Negative & 98 & 70 & 52 & 40 & \\
\hline Positive & 14 & 27 & 14 & 8 & \\
\hline Differentiation & & & & & 0.310 \\
\hline Good & 17 & 10 & 12 & 5 & \\
\hline Moderate & 80 & 65 & 41 & 30 & \\
\hline Poor & 15 & 22 & 13 & 13 & \\
\hline T stage & & & & & $<0.001$ \\
\hline $\mathrm{T} 1$ & 33 & 18 & 3 & 1 & \\
\hline $\mathrm{T} 2$ & 23 & 14 & 11 & 7 & \\
\hline T3 & 50 & 58 & 42 & 29 & \\
\hline $\mathrm{T} 4$ & 6 & 7 & 10 & 11 & \\
\hline $\mathrm{N}$ stage & & & & & $<0.001$ \\
\hline No & 71 & 55 & 32 & 16 & \\
\hline N1 & 30 & 30 & 12 & 15 & \\
\hline $\mathrm{N} 2$ & 6 & 9 & 12 & 10 & \\
\hline N3 & 5 & 3 & 10 & 7 & \\
\hline TNM stage & & & & & $<0.001$ \\
\hline I & 46 & 21 & 9 & 5 & \\
\hline II & 31 & 41 & 22 & 10 & \\
\hline III & 35 & 35 & 35 & 33 & \\
\hline
\end{tabular}

Pearson correlation analyses were performed to analyse the correlation. Receiver operating characteristic (ROC) curves were plotted to determine the accuracy of CRP, NLR, and PLR. A $P<0.05$ was considered to be statistically significant. Statistical analyses were conducted with SPSS 17.0 (SPSS Inc., Chicago, IL, USA).

\section{Results}

Clinicopathologic characters were shown in Table 1. The mean CRP, NLR, and PLR were $9.7 \pm 13.5(\mathrm{mg} / \mathrm{L}), 3.3 \pm$ 2.8 , and $160.9 \pm 70.6$, respectively. The histograms of CRP, 


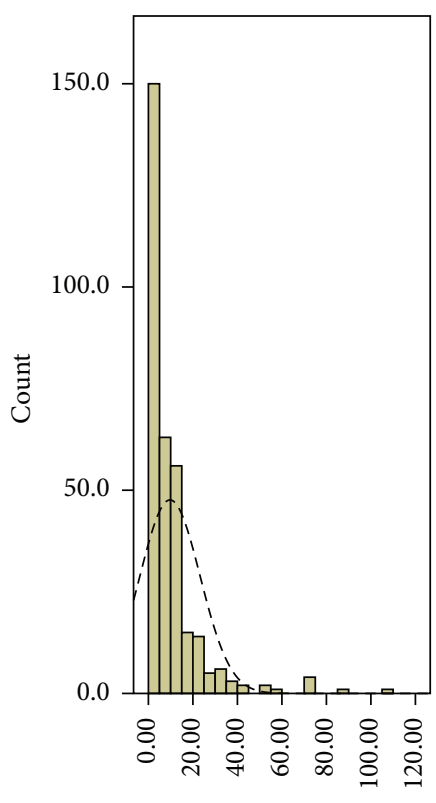

CRP

(a)

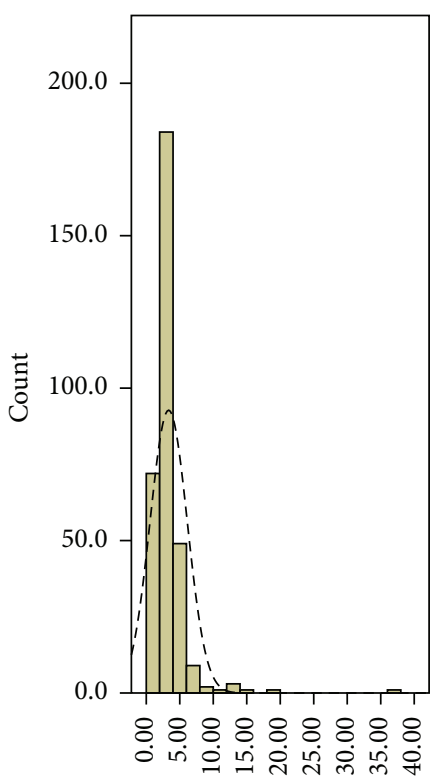

NLR

(b)

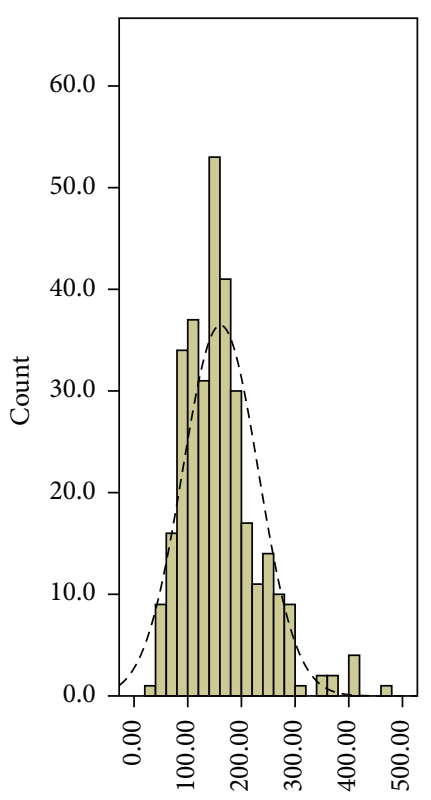

PLR

(c)

Figure 1: The histograms of the CRP (a), NLR (b), and PLR (c).

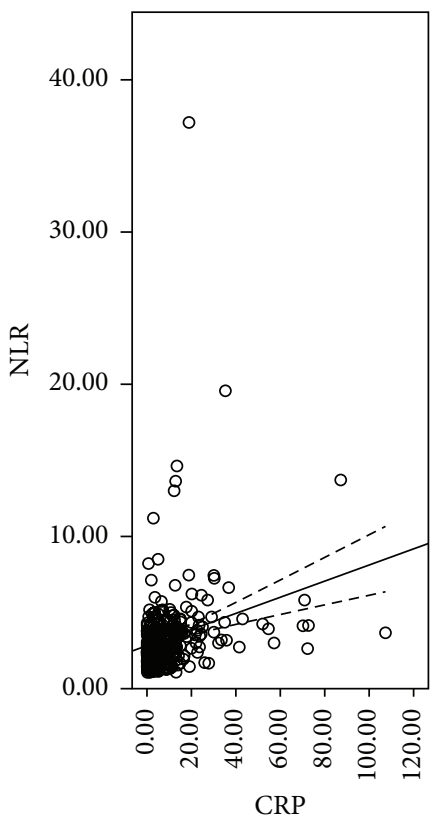

(a)

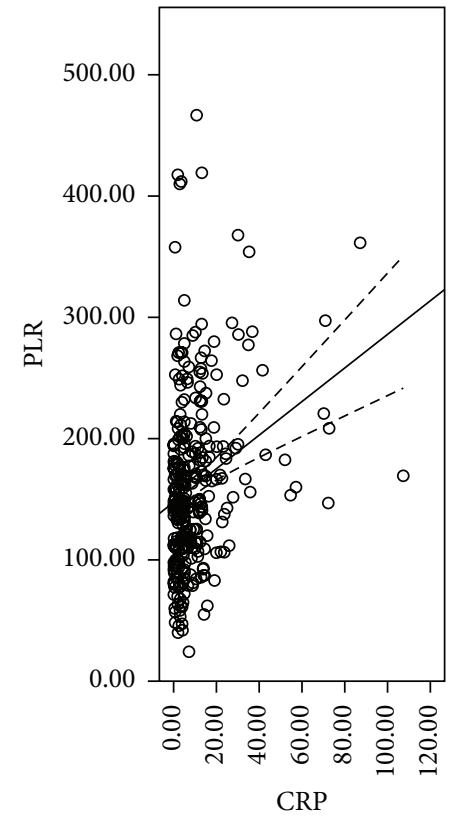

(b)

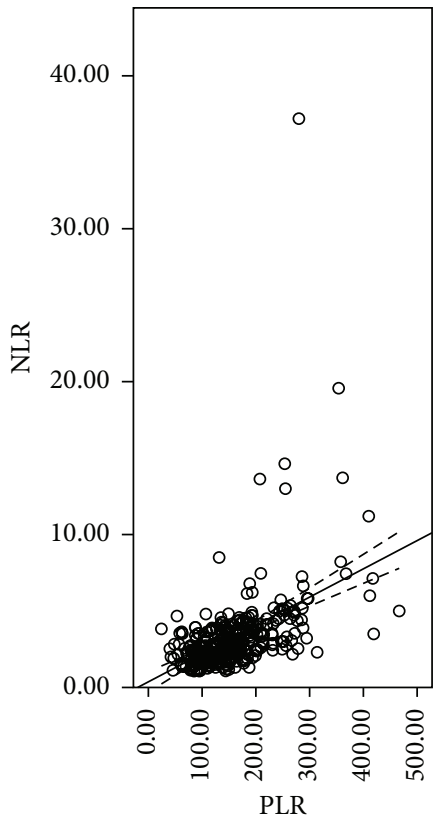

(c)

FIgURE 2: Pearson correlation analysis. Positive correlations in CRP and NLR $(r=0.258, P<0.001$; (a)), CRP and PLR $(r=0.265, P<0.001$; (b)), and NLR and PLR $(r=0.470, P<0.001 ;(\mathrm{c}))$.

NLR, and PLR were shown in Figure 1. There were significant positive correlations in CRP and NLR $(r=0.258, P<0.001)$, CRP and PLR $(r=0.265, P<0.001)$, and NLR and PLR $(r=0.470, P<0.001)$ (Figure 2 ). ROC curves for CSS prediction were shown in Figure 3. The area under the curve (AUC) was 0.713 (95\% CI: $0.653-0.772, P<0.001$ ) for CRP,
0.650 (95\% CI: $0.589-0.711, P<0.001)$ for NLR, and 0.685 (95\% CI: $0.626-0.744, P<0.001)$ for PLR.

Of the 323 patients, $112(34.7 \%)$ were allocated an I stage 0, 97 (30.0\%) were allocated an I stage 1, 66 (20.4\%) were allocated an I stage 2, and 48 (14.9\%) were allocated an I stage 3 , respectively. The relationships between the I stage 


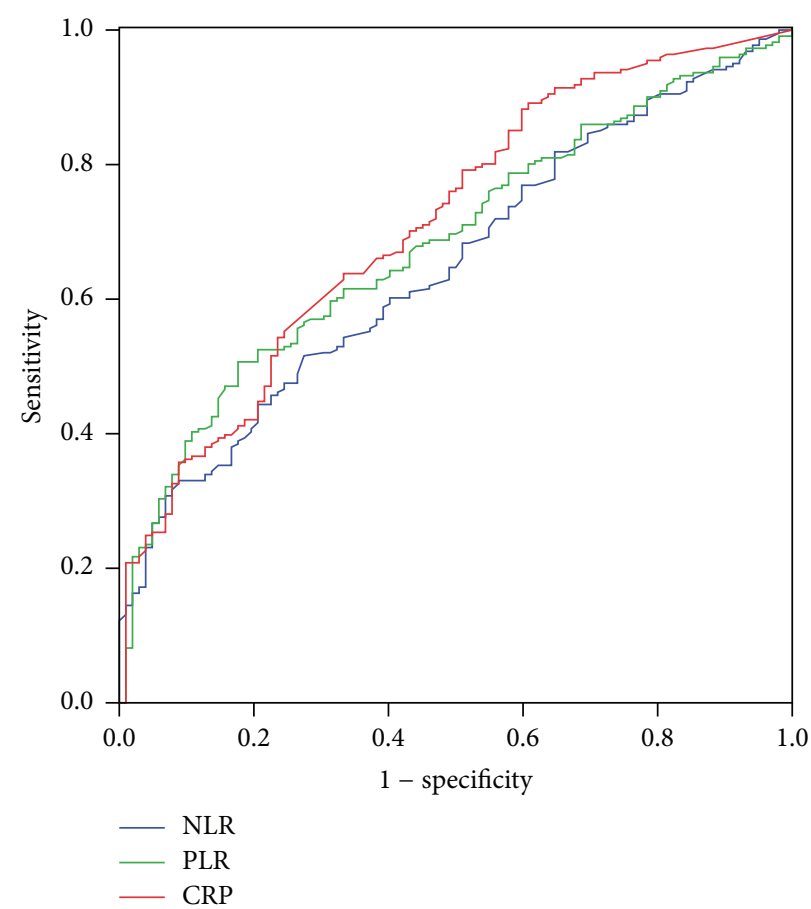

FIgURE 3: ROC curves for CSS prediction. The area under the curve (AUC) was 0.713 (95\% CI: $0.653-0.772, P<0.001$ ) for CRP, 0.650 (95\% CI: 0.589-0.711, $P<0.001)$ for NLR, and 0.685 (95\% CI: $0.626-0.744, P<0.001)$ for PLR.

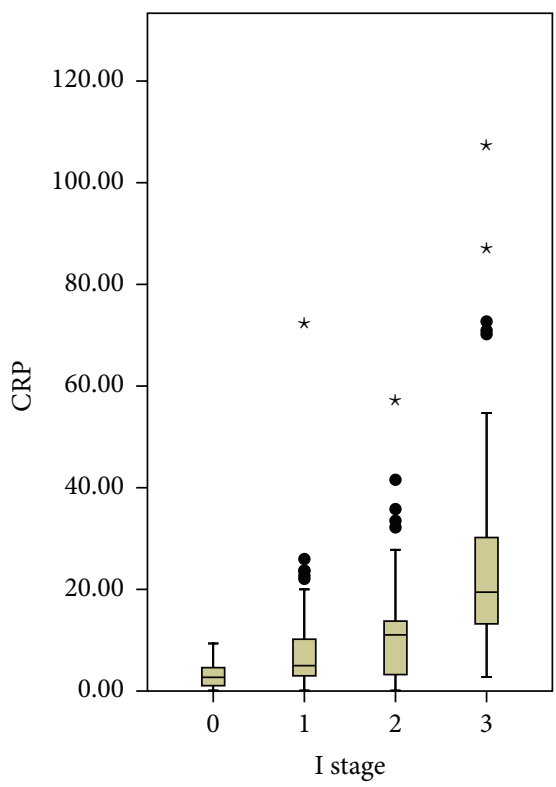

(a)

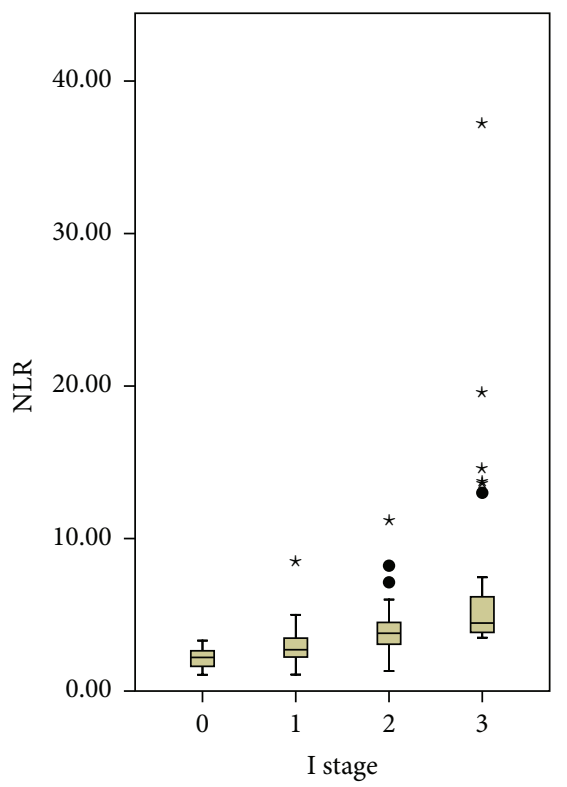

(b)

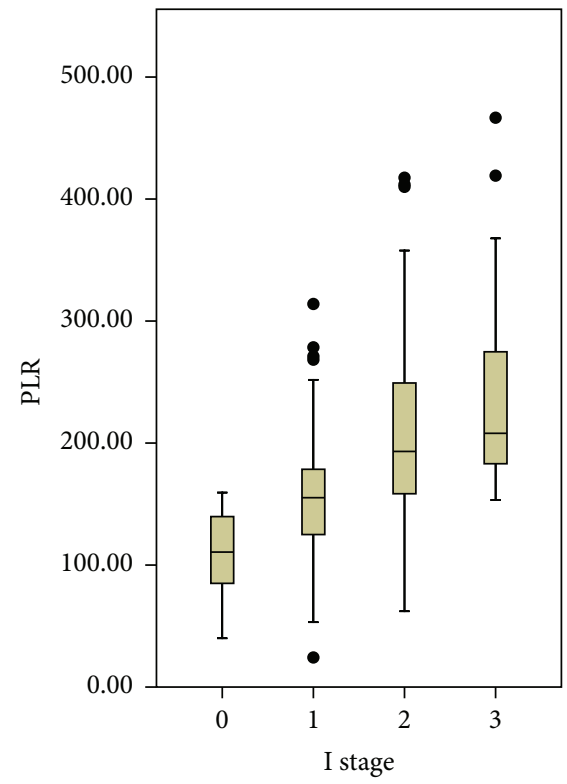

(c)

Figure 4: The CRP (a), NLR (b), and PLR (c) were significantly higher in patients with high I stage $(P<0.001)$. The “*” and “•” were created by SPSS statistical software.

and clinicopathological characteristics were shown in Table 2. Our study demonstrated that I stage was associated with tumor length $(P<0.001)$, perineural invasion $(P=0.043)$, T stage $(P<0.001), \mathrm{N}$ stage $(P<0.001)$, and TNM stage $(P<0.001)$. In addition, our study revealed that CRP, NLR, and PLR were significantly higher in patients with high I stage $(P<0.001$, Figure 4$)$.

The 5-year CSS in patients with I0, I1, I2, and I3 was $50.0 \%, 30.9 \%, 18.2 \%$, and $8.3 \%$, respectively $(P<0.001$, Figure 5) (I0 versus I1, $P=0.002$; I1 versus I2, $P=0.012$; 
TABLE 3: Univariate analyses for patients with ESCC.

\begin{tabular}{|c|c|c|c|c|}
\hline & 5-year CSS (\%) & $P$ value & $\operatorname{HR}(95 \% \mathrm{CI})$ & $P$ value \\
\hline Age (years) & & 0.978 & & 0.978 \\
\hline$\leq 60$ & 30.1 & & 1.000 & \\
\hline$>60$ & 33.6 & & $0.996(0.762-1.302)$ & \\
\hline Gender & & 0.322 & & 0.327 \\
\hline Female & 38.1 & & 1.000 & \\
\hline Male & 30.6 & & $1.227(0.815-1.848)$ & \\
\hline Tumor length $(\mathrm{cm})$ & & 0.003 & & 0.004 \\
\hline$\leq 3$ & 41.6 & & 1.000 & \\
\hline$>3$ & 27.8 & & $1.580(1.157-2.157)$ & \\
\hline Tumor location & & 0.556 & & 0.564 \\
\hline Upper & 41.2 & & 1.000 & \\
\hline Middle & 33.1 & & $0.735(0.385-1.404)$ & 0.351 \\
\hline Lower & 29.0 & & $0.908(0.693-1.190)$ & 0.483 \\
\hline Differentiation & & 0.198 & & 0.207 \\
\hline Good & 38.6 & & 1.000 & \\
\hline Moderate & 31.0 & & $1.185(0.786-1.786)$ & 0.417 \\
\hline Poor & 28.6 & & $1.504(0.933-2.424)$ & 0.098 \\
\hline Vessel involvement & & 0.007 & & 0.008 \\
\hline Negative & 34.1 & & 1.000 & \\
\hline Positive & 18.9 & & $1.577(1.129-2.202)$ & \\
\hline Perineural invasion & & 0.005 & & 0.006 \\
\hline Negative & 35.0 & & 1.000 & \\
\hline Positive & 17.5 & & $1.551(1.135-2.119)$ & \\
\hline TNM stage & & $<0.001$ & & $<0.001$ \\
\hline I & 51.9 & & 1.000 & \\
\hline II & 32.7 & & $1.878(1.269-2.780)$ & 0.002 \\
\hline III & 18.8 & & $2.943(2.039-4.248)$ & $<0.001$ \\
\hline I stage & & $<0.001$ & & $<0.001$ \\
\hline I0 & 50.0 & & 1.000 & \\
\hline I1 & 30.9 & & $1.696(1.189-2.420)$ & 0.004 \\
\hline $\mathrm{I} 2$ & 18.2 & & $2.676(1.837-3.900)$ & $<0.001$ \\
\hline I3 & 8.3 & & $4.372(2.924-6.536)$ & $<0.001$ \\
\hline Adjuvant therapy & & 0.398 & & 0.402 \\
\hline No & 32.0 & & 1.000 & \\
\hline Yes & 30.6 & & $1.130(0.849-1.504)$ & \\
\hline CRP (mg/L) & & $<0.001$ & & $<0.001$ \\
\hline$\leq 10.0$ & 39.2 & & 1.000 & \\
\hline$>10.0$ & 17.1 & & $2.217(1.692-2.906)$ & \\
\hline NLR & & $<0.001$ & & $<0.001$ \\
\hline$\leq 3.5$ & 39.0 & & 1.000 & \\
\hline$>3.5$ & 17.7 & & $1.925(1.471-2.519)$ & \\
\hline PLR & & $<0.001$ & & $<0.001$ \\
\hline$\leq 150$ & 43.9 & & 1.000 & \\
\hline$>150$ & 17.3 & & $2.260(1.729-2.955)$ & \\
\hline
\end{tabular}

I2 versus $\mathrm{I} 3, P=0.020)$. In addition, our study revealed that patients with CRP $(>10.0 \mathrm{mg} / \mathrm{L})$, NLR $(>3.5)$, or PLR $(>150)$ were significantly associated with decreased CSS, respectively $(P<0.001)$. Then, we further stratified patients into different groups based on TNM stage. Our results demonstrated that
I stage was also significantly correlated with CSS based on TNM stage (Figure 6).

Among the above variables, univariate analyses revealed that tumor length $(P=0.004)$, vessel involvement $(P=$ $0.008)$, perineural invasion $(P=0.006)$, TNM stage 

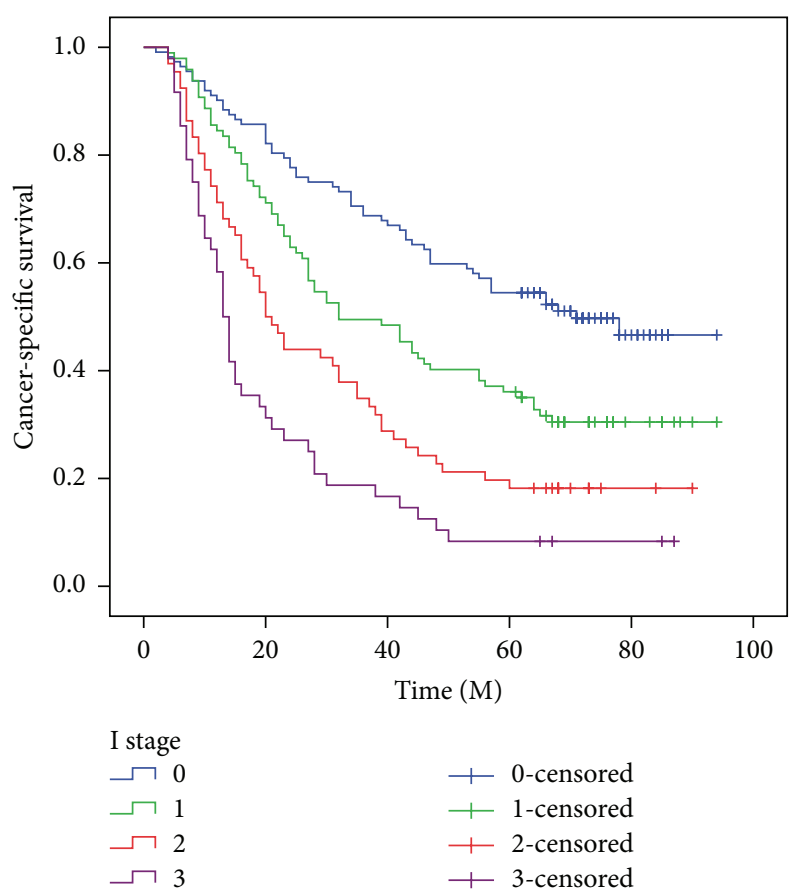

FIGURE 5: The 5-year CSS in patients with I0, I1, I2, and I3 was 50.0\%, $30.9 \%, 18.2 \%$, and $8.3 \%$, respectively $(P<0.001)$ (I0 versus I1, $P=$ 0.002 ; I1 versus $\mathrm{I} 2, P=0.012$; $\mathrm{I} 2$ versus $\mathrm{I} 3, P=0.020$ ).

$(P<0.001)$, and I stage $(P<0.001)$ were predictive of CSS (Table 3). In multivariate analyses, we demonstrated that I stage was an independent prognostic factor in patients with resectable ESCC $(P<0.001)$ (Table 4$)$.

\section{Discussion}

In the current study, we initially proposed a novel inflammation-based prognostic system, named I stage (combination of CRP, NLR, and PLR), in patients with resectable ESCC. Our study revealed that I stage was associated with tumor length, perineural invasion, and TNM stage. In multivariate analyses, we revealed that I stage is a useful predictor of postoperative CSS in patients with resectable ESCC $(P<$ 0.001).

Several hematological biomarkers have shown prognostic values in cancers. In particular, the CRP has been well validated. CRP is a representative acute-phase reactant for inflammation [19]. Recently, several previous studies have shown that CRP is associated with prognosis in several cancers, including ECs [6, 8-12]. In our study, patients with CRP $\leq 10.0 \mathrm{mg} / \mathrm{L}$ had a significantly better 5-year CSS than patients with CRP > $10.0 \mathrm{mg} / \mathrm{L}(39.2 \%$ versus $17.1 \%, P<$ $0.001)$. However, CRP was not an independent prognostic factor in multivariate analyses $(P=0.493)$.

The prognostic values of NLR and PLR in patients with EC remain uncertain. Several reports demonstrated that NLR is an independent prognostic factor in patients with EC [14, 15]. However, Rashid et al. [13] and Dutta et al. [16] revealed that NLR does not correlate with prognosis for patients with
TABLE 4: Multivariate analyses for patients with ESCC.

\begin{tabular}{|c|c|c|}
\hline & $\mathrm{HR}(95 \% \mathrm{CI})$ & $P$ value \\
\hline Tumor length $(\mathrm{cm})$ & & 0.603 \\
\hline$\leq 3$ & 1.000 & \\
\hline$>3$ & $1.075(0.818-1.412)$ & \\
\hline Vessel involvement & & 0.742 \\
\hline Negative & 1.000 & \\
\hline Positive & $1.060(0.747-1.505)$ & \\
\hline Perineural invasion & & 0.077 \\
\hline Negative & 1.000 & \\
\hline Positive & $1.341(0.968-1.857)$ & \\
\hline TNM stage & & $<0.001$ \\
\hline I & 1.000 & \\
\hline II & $1.586(1.048-2.400)$ & 0.029 \\
\hline III & $2.220(1.456-3.384)$ & $<0.001$ \\
\hline I stage & & $<0.001$ \\
\hline I0 & 1.000 & \\
\hline I1 & $1.543(1.076-2.214)$ & 0.018 \\
\hline $\mathrm{I} 2$ & $2.356(1.602-3.466)$ & $<0.001$ \\
\hline I3 & $3.594(2.363-5.467)$ & $<0.001$ \\
\hline CRP (mg/L) & & 0.493 \\
\hline$\leq 10.0$ & 1.000 & \\
\hline$>10.0$ & $1.151(0.770-1.719)$ & \\
\hline NLR & & 0.786 \\
\hline$\leq 3.5$ & 1.000 & \\
\hline$>3.5$ & $1.050(0.740-1.488)$ & \\
\hline PLR & & 0.065 \\
\hline$\leq 150$ & 1.000 & \\
\hline$>150$ & $1.440(0.978-2.121)$ & \\
\hline
\end{tabular}

EC. Moreover, there have been few studies regarding PLR in EC patients. Dutta et al. [16] demonstrated that PLR does not correlate with prognosis in patients with EC. A retrospective study by Liu et al. [20] on 326 ESCC patients revealed PLR to be a potential prognostic factor. In our study, NLR and PLR were correlated with survival; however, NLR and PLN were not independent prognostic factors in multivariate analyses.

At present, the prognosis of cancer is commonly based on the TNM staging system [21, 22]. Inflammation plays an important role in cancer. Therefore, in our study, we proposed a novel inflammation-based prognostic system (I stage) in resectable ESCC patients. A significant association was found between the I stage and clinical characteristics. In multivariate analyses, we revealed that I stage is a useful predictor of postoperative CCS in patients with resectable ESCC $(P<0.001)$. It may well be that the influence of I stage on the subgroup with TNM stage is important for the understanding of its role in patients with ESCC. Our results demonstrated that I stage was also significantly correlated with CSS based on TNM stage.

Limitations should be acknowledged. Firstly, our study was a retrospective study. Secondly, we excluded patients with neoadjuvant treatment, which may have influenced the results. Neoadjuvant treatment will inevitably have an impact 

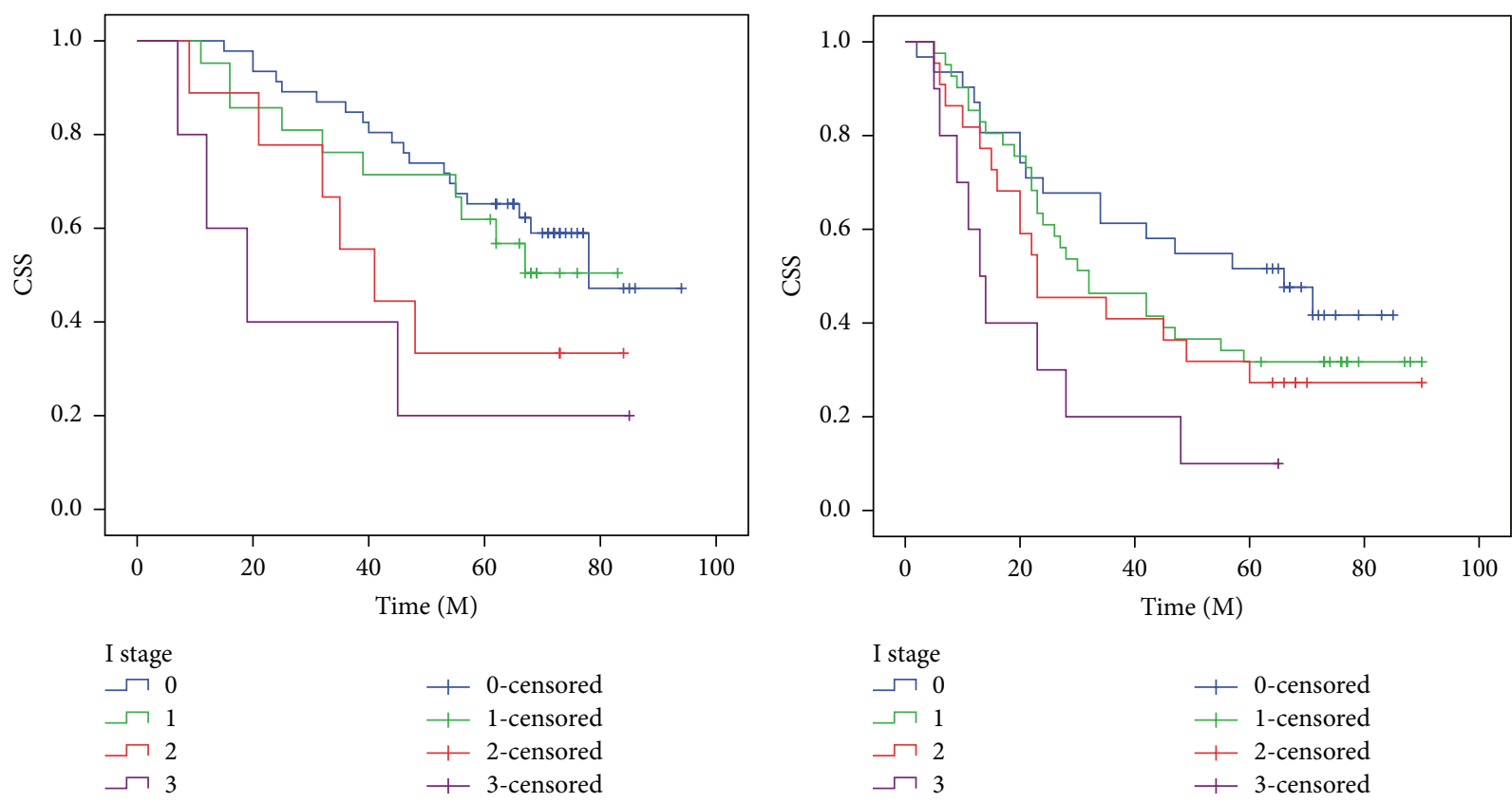

(a)

(b)
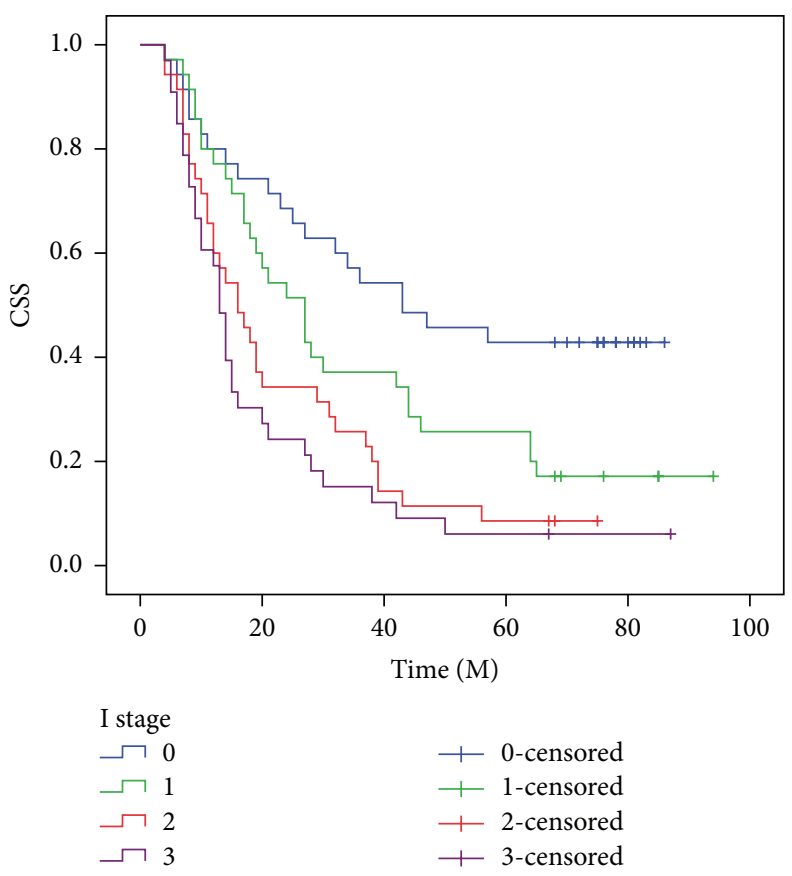

(c)

Figure 6: The predictive values of I stage were significant in patients based on TNM stage. TNM I stage $(P=0.035$, (a)), TNM II stage $(P=0.028,(b))$, and TNM III stage $(P<0.001,(c))$.

on the systemic inflammation. Thus, evaluation of I stage in neoadjuvant therapy does not reflect the baseline impact of systemic inflammation for ESCC patients. Therefore, larger prospective studies will need to be performed to confirm these preliminary results.

In summary, there was a significant association between the I stage (combination of CRP, NLR, and PLR) and clinical characteristics. Based on the results of the current study, we believe that I stage is a novel and useful predictive factor for CSS in patients with resectable ESCC.

\section{Competing Interests}

The authors have no competing interests to disclose. 


\section{References}

[1] R. L. Siegel, K. D. Miller, and A. Jemal, "Cancer statistics, 2015," CA: A Cancer Journal for Clinicians, vol. 65, no. 1, pp. 5-29, 2015.

[2] Y. Lin, Y. Totsuka, Y. He et al., "Epidemiology of esophageal cancer in Japan and China," Journal of Epidemiology, vol. 23, no. 4, pp. 233-242, 2013.

[3] K. K. Keditsu, S. Jiwnani, G. Karimundackal, and C. S. Pramesh, "Multimodality management of esophageal cancer," Indian Journal of Surgical Oncology, vol. 4, no. 2, pp. 96-104, 2013.

[4] F. Balkwill and A. Mantovani, "Inflammation and cancer: back to Virchow?" The Lancet, vol. 357, no. 9255, pp. 539-545, 2001.

[5] A. Mantovani, P. Allavena, A. Sica, and F. Balkwill, "Cancerrelated inflammation," Nature, vol. 454, no. 7203, pp. 436-444, 2008.

[6] T. Nakamura, A. Matsumine, K. Asanuma, T. Matsubara, and A. Sudo, "The role of C-reactive protein in predicting postmetastatic survival of patients with metastatic bone and soft tissue sarcoma," Tumor Biology, vol. 36, no. 10, pp. 7515-7520, 2015.

[7] N. Jiang, J.-Y. Deng, Y. Liu, B. Ke, H.-G. Liu, and H. Liang, "The role of preoperative neutrophil-lymphocyte and plateletlymphocyte ratio in patients after radical resection for gastric cancer," Biomarkers, vol. 19, no. 6, pp. 444-451, 2014.

[8] T. Nozoe, T. Iguchi, E. Adachi, A. Matsukuma, and T. Ezaki, "Preoperative elevation of serum C-reactive protein as an independent prognostic indicator for gastric cancer," Surgery Today, vol. 41, no. 4, pp. 510-513, 2011.

[9] T. Nakamura, A. Matsumine, T. Matsubara, K. Asanuma, A. Uchida, and A. Sudo, "The combined use of the neutrophillymphocyte ratio and C-reactive protein level as prognostic predictors in adult patients with soft tissue sarcoma," Journal of Surgical Oncology, vol. 108, no. 7, pp. 481-485, 2013.

[10] T. Nakamura, R. J. Grimer, C. L. Gaston, M. Watanuki, A. Sudo, and L. Jeys, "The prognostic value of the serum level of C-reactive protein for the survival of patients with a primary sarcoma of bone," Bone \& Joint Journal B, vol. 95, no. 3, pp. 411418, 2013.

[11] T. Nakamura, R. Grimer, C. Gaston et al., "The value of Creactive protein and comorbidity in predicting survival of patients with high grade soft tissue sarcoma," European Journal of Cancer, vol. 49, no. 2, pp. 377-385, 2013.

[12] H. Shimada, Y. Nabeya, S.-I. Okazumi et al., "Elevation of pre-operative serum C-reactive protein level is related to poor prognosis in esophageal squamous cell carcinoma," Journal of Surgical Oncology, vol. 83, no. 4, pp. 248-252, 2003.

[13] F. Rashid, N. Waraich, I. Bhatti et al., "A pre-operative elevated neutrophil: lymphocyte ratio does not predict survival from oesophageal cancer resection," World Journal of Surgical Oncology, vol. 8, article 1, 2010.

[14] H. Sato, Y. Tsubosa, and T. Kawano, "Correlation between the pretherapeutic neutrophil to lymphocyte ratio and the pathologic response to neoadjuvant chemotherapy in patients with advanced esophageal cancer," World Journal of Surgery, vol. 36, no. 3, pp. 617-622, 2012.

[15] R. Z. Sharaiha, K. J. Halazun, F. Mirza et al., "Elevated preoperative neutrophil: lymphocyte ratio as a predictor of postoperative disease recurrence in esophageal cancer," Annals of Surgical Oncology, vol. 18, no. 12, pp. 3362-3369, 2011.

[16] S. Dutta, A. B. C. Crumley, G. M. Fullarton, P. G. Horgan, and D. C. McMillan, "Comparison of the prognostic value of tumour- and patient-related factors in patients undergoing potentially curative resection of oesophageal cancer," World Journal of Surgery, vol. 35, no. 8, pp. 1861-1866, 2011.

[17] J.-F. Feng, Y. Huang, and Q.-X. Chen, "Preoperative platelet lymphocyte ratio (PLR) is superior to neutrophil lymphocyte ratio (NLR) as a predictive factor in patients with esophageal squamous cell carcinoma," World Journal of Surgical Oncology, vol. 12, article 58, 2014.

[18] T. W. Rice, V. W. Rusch, H. Ishwaran, and E. H. Blackstone, "Cancer of the esophagus and esophagogastric junction: datadriven staging for the seventh edition of the American Joint Committee on Cancer/International Union Against Cancer Cancer Staging Manuals," Cancer, vol.116, no. 16, pp. 3763-3773, 2010.

[19] E. E. Diehl, G. K. Haines III, J. A. Radosevich, and L. A. Potempa, "Immunohistochemical localization of modified Creactive protein antigen in normal vascular tissue," The American Journal of the Medical Sciences, vol. 319, no. 2, pp. 79-83, 2000.

[20] J. S. Liu, Y. Huang, X. Yang, and J. F. Feng, "A nomogram to predict prognostic values of various inflammatory biomarkers in patients with esophagealsquamous cell carcinoma," American Journal of Cancer Research, vol. 5, pp. 2180-2189, 2015.

[21] B. P. L. Wijnhoven, K. T. C. Tran, A. Esterman, D. I. Watson, and H. W. Tilanus, "An evaluation of prognostic factors and tumor staging of resected carcinoma of the esophagus," Annals of Surgery, vol. 245, no. 5, pp. 717-725, 2007.

[22] C. G. Peyre, J. A. Hagen, S. R. DeMeester et al., "The number of lymph nodes removed predicts survival in esophageal cancer: an international study on the impact of extent of surgical resection," Annals of Surgery, vol. 248, no. 4, pp. 549-556, 2008. 


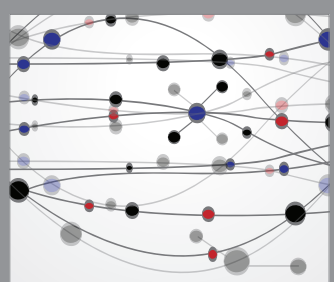

The Scientific World Journal
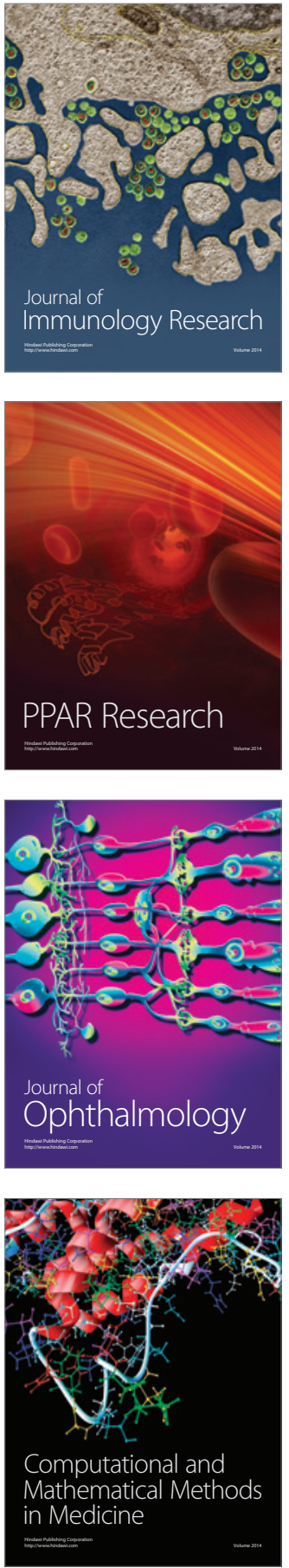

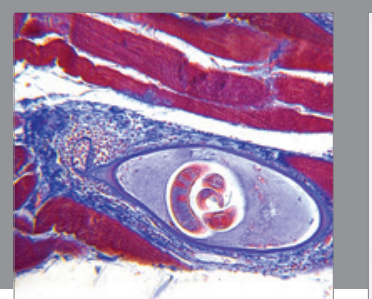

Gastroenterology Research and Practice

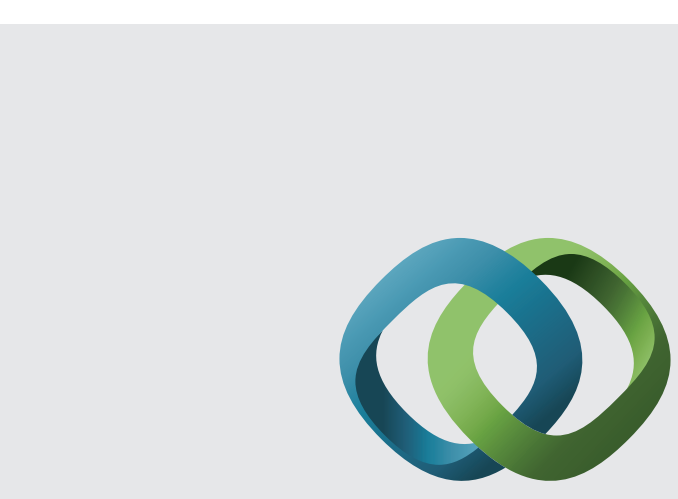

\section{Hindawi}

Submit your manuscripts at

http://www.hindawi.com
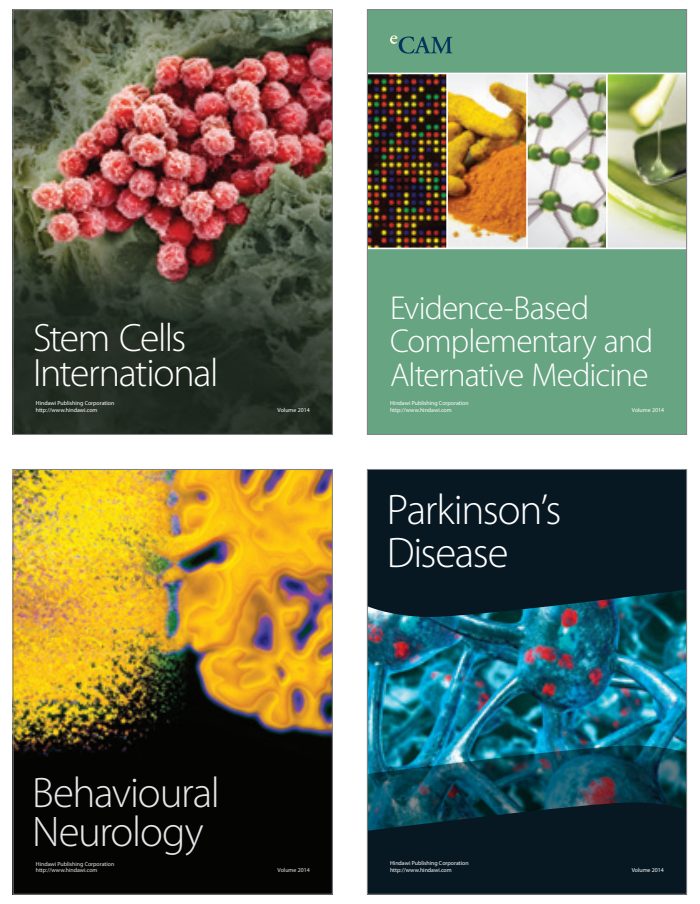
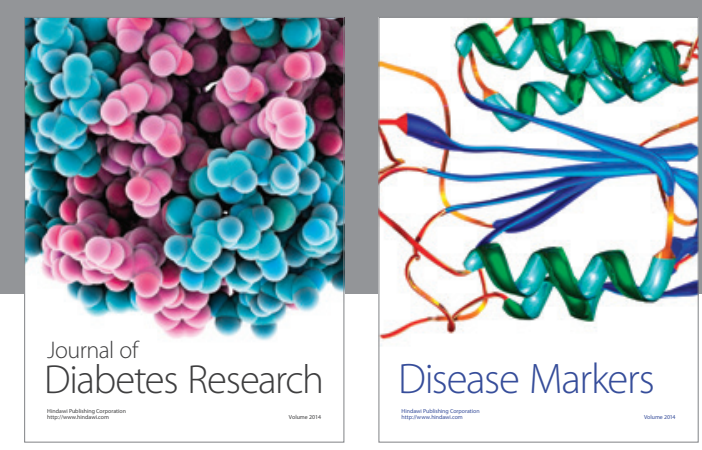

Disease Markers
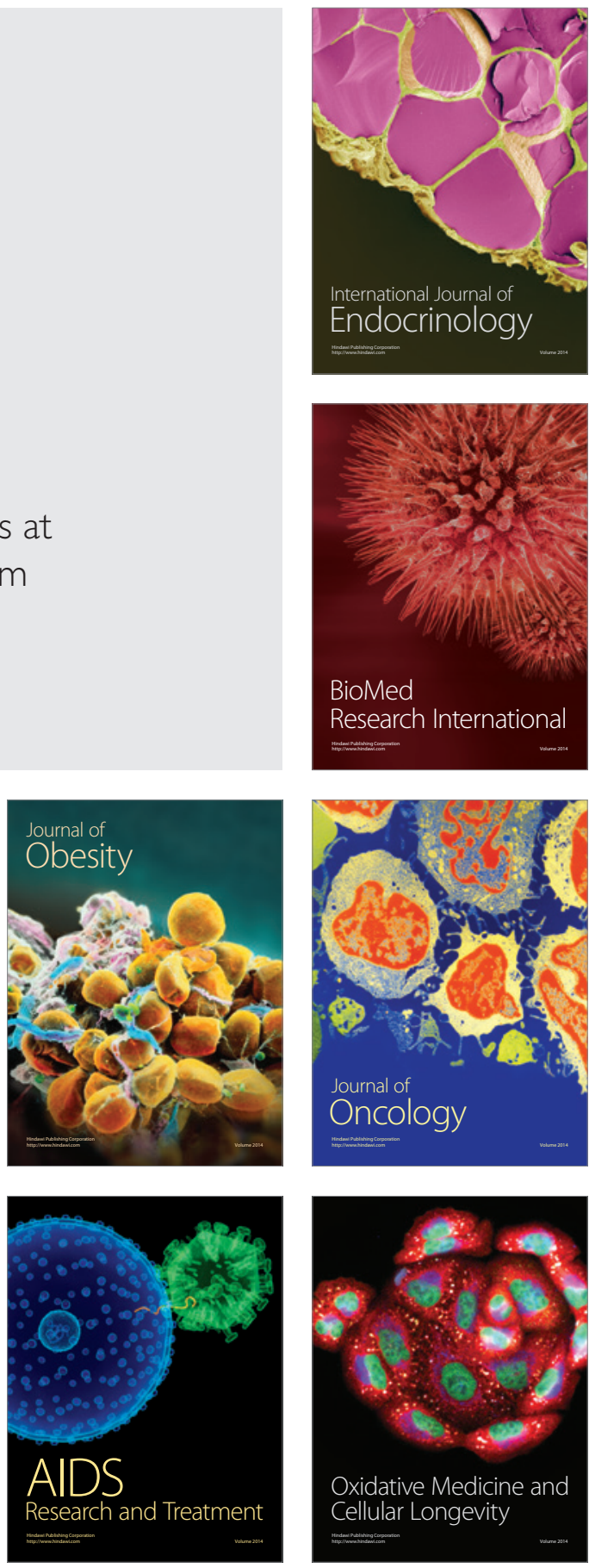